\title{
Common fixed points of a family of strictly pseudocontractive mappings
}

\author{
Xiaolong Qin' ${ }^{1}$, Meijuan Shang ${ }^{2,3^{*}}$ and Yuan Qing ${ }^{1}$
}

\author{
*Correspondence: \\ meijuanshang@163.com \\ ${ }^{2}$ Department of Mathematics, \\ Shijiazhuang University, \\ Shijiazhuang, China \\ ${ }^{3}$ School of Science, Beijing Jiaotong \\ University, Beijing, China \\ Full list of author information is \\ available at the end of the article
}

\begin{abstract}
In this article, fixed point problems of a family of strictly pseudocontractive mappings are investigated based on a viscosity iterative process. Strong convergence theorems are established in a real q-uniformly Banach space.

MSC: 47H09; 47J05; 47J25

Keywords: accretive operator; iterative process; fixed point; nonexpansive mapping; zero point
\end{abstract}

\section{Introduction}

Fixed point problems of nonlinear mappings as an important branch of nonlinear analysis theory have been applied in many disciplines, including economics, optimization, image recovery, mechanics, quantum physics, transportation and control theory; for more details, see [1-31] and the references therein.

Strictly pseudocontractive mappings, which act as a link between nonexpansive mappings and pseudocontractive mappings, have been extensively studied by many authors; see [20-31] and the references therein. The computation of fixed points is important in the study of many real world problems, including inverse problems; for instance, it is not hard to show that the split feasibility problem and the convex feasibility problem in signal processing and image reconstruction can both be formulated as a problem of finding fixed points of certain operators, respectively.

Recently, many authors studied the following convex feasibility problem (CFP): $x \in$ $\bigcap_{i=1}^{N} \Omega_{i}$, where $N \geq 1$ is an integer, and each $\Omega_{i}$ is assumed to be the fixed point set of a nonlinear mapping $T_{i}, i=1,2, \ldots, N$. There is a considerable investigation on CFP in the setting of Hilbert spaces which captures applications in various disciplines such as image restoration [32], computer tomography [33] and radiation therapy treatment planning [34].

In this paper, we investigate the problem of finding a common fixed point of a finite family of strictly pseudocontractive mappings based on a viscosity approximation iterative process. Strong convergence theorems of common fixed points are established in a real $q$-uniformly Banach space.

@2013 Qin et al:; licensee Springer. This is an Open Access article distributed under the terms of the Creative Commons Attribution License (http://creativecommons.org/licenses/by/2.0), which permits unrestricted use, distribution, and reproduction in any medium, provided the original work is properly cited. 


\section{Preliminaries}

Throughout this paper, we always assume that $E$ is a real Banach space. Let $E^{*}$ be the dual space of $E$. Let $J_{q}(q>1)$ denote the generalized duality mapping from $E$ into $2^{E^{*}}$ given by

$$
J_{q}(x)=\left\{f^{*} \in E^{*}:\left\langle x, f^{*}\right\rangle=\|x\|^{q},\left\|f^{*}\right\|=\|x\|^{q-1}\right\}, \quad \forall x \in E,
$$

where $\langle\cdot, \cdot\rangle$ denotes the generalized duality pairing. In particular, $J_{2}$ is called the normalized duality mapping, which is usually denoted by $J$. In this paper, we use $j$ to denote the singlevalued normalized duality mapping. It is known that $J_{q}(x)=\|x\|^{q-2} J(x)$ if $x \neq 0$. If $E$ is a Hilbert space, then $J=I$, the identity mapping. Further, we have the following properties of the generalized duality mapping $J_{q}$ :

(1) $J_{q}(t x)=t^{q-1} J_{q}(x)$ for all $x \in E$ and $t \in[0, \infty)$;

(2) $J_{q}(-x)=-J_{q}(x)$ for all $x \in E$.

A Banach space $E$ is said to be smooth if the limit

$$
\lim _{t \rightarrow 0} \frac{\|x+t y\|-\|x\|}{t}
$$

exists for all $x, y \in U_{E}$. It is also said to be uniformly smooth if the limit is attained uniformly for all $x, y \in U_{E}$. The norm of $E$ is said to be Fréchet differentiable if, for any $x \in U_{E}$, the above limit is attained uniformly for all $y \in U_{E}$. The modulus of smoothness of $E$ is the function $\rho_{E}:[0, \infty) \rightarrow[0, \infty)$ defined by

$$
\rho_{E}(\tau)=\sup \left\{\frac{1}{2}(\|x+y\|+\|x-y\|)-1:\|x\| \leq 1,\|y\| \leq \tau\right\}, \quad \forall \tau \geq 0 .
$$

The Banach space $E$ is uniformly smooth if and only if $\lim _{\tau \rightarrow \infty} \frac{\rho_{E}(\tau)}{\tau}=0$. Let $q>1$. The Banach space $E$ is said to be $q$-uniformly smooth if there exists a constant $c>0$ such that $\rho_{E}(\tau) \leq c \tau^{q}$. Indeed, there is no Banach space which is $q$-uniformly smooth with $q>2$. Hilbert spaces, $L^{p}$ (or $l^{p}$ ) spaces and Sobolev spaces $W_{m}^{p}$, where $p \geq 2$, are 2-uniformly smooth.

Let $C$ be a nonempty closed convex subset of $E$ and $T: C \rightarrow C$ be a mapping. In this paper, we use $F(T)$ to denote the fixed point set of $T$. A mapping $T$ is said to be $\kappa$-contractive iff there exists a constant $\kappa \in(01)$ such that

$$
\|T x-T y\| \leq \kappa\|x-y\|, \quad \forall x, y \in C .
$$

A mapping $T$ is said to be nonexpansive iff

$$
\|T x-T y\| \leq\|x-y\|, \quad \forall x, y \in C .
$$

A mapping $T$ is said to be $\kappa$-strictly pseudocontractive iff there exist a constant $\kappa \in(0,1)$ and $j_{q}(x-y) \in J_{q}(x-y)$ such that

$$
\left\langle T x-T y, j_{q}(x-y)\right\rangle \leq\|x-y\|^{q}-\kappa\|(I-T) x-(I-T) y\|^{q}, \quad \forall x, y \in C .
$$

It is clear that (2.1) is equivalent to the following:

$$
\left\langle(I-T) x-(I-T) y, j_{q}(x-y)\right| \geq \kappa\|(I-T) x-(I-T) y\|^{q}, \quad \forall x, y \in C .
$$


The class of $\kappa$-strictly pseudocontractive mappings was first introduced by Browder and Petryshyn [35] in Hilbert spaces.

One classical way to study nonexpansive mappings is to use contractions to approximate a nonexpansive mapping. More precisely, take $t \in(0,1)$ and define a contraction $T_{t}: C \rightarrow$ $C$ by

$$
T_{t} x=t u+(1-t) T x, \quad \forall x \in C,
$$

where $u \in C$ is a fixed point. Banach's contraction mapping principle guarantees that $T_{t}$ has a unique fixed point $x_{t}$ in $C$. In the case of $T$ having a fixed point, Browder [36] proved that $x_{t}$ converges strongly to a fixed point of $T$ in the framework of Hilbert spaces. Reich [37] extended Browder's result to the setting of Banach spaces and proved that if $E$ is a uniformly smooth Banach space, then $x_{t}$ converges strongly to a fixed point of $T$, and the limit defines the (unique) sunny nonexpansive retraction from $C$ onto $F(T)$; for more details, see [37] and the reference therein.

Recently, Xu [38] investigated the viscosity approximation process in a smooth Banach space. Let $f: C \rightarrow C$ be a contraction. Take $t \in(0,1)$ and define a mapping $T_{t}: C \rightarrow C$ by

$$
T_{t} x=t f(x)+(1-t) T x, \quad \forall x \in C .
$$

It is not hard to see that $T_{t}$ also enjoys a unique fixed point. Xu proved that $\left\{z_{t}\right\}$ converges to a fixed point of $T$ as $t \rightarrow 0$, and $Q(f)=s-\lim _{t \rightarrow 0} z_{t}$ defines the unique sunny nonexpansive retraction from $C$ onto $F(T)$.

Recently, construction of fixed points for nonexpansive mappings via the normal Mann iterative process has been extensively investigated by many authors. The normal Mann iterative process generates a sequence $\left\{x_{n}\right\}$ in the following manner:

$$
\left\{\begin{array}{l}
x_{1} \in C \quad \text { chosen arbitrarily, } \\
x_{n+1}=\left(1-\alpha_{n}\right) x_{n}+\alpha_{n} T x_{n}, \quad \forall n \geq 1,
\end{array}\right.
$$

where the sequence $\left\{\alpha_{n}\right\}$ is in the interval $(0,1)$.

In an infinite-dimensional Hilbert space, the normal Mann iteration algorithm has only weak convergence. In many disciplines, including economics, image recovery and control theory, problems arise in infinite dimension spaces. In such problems, strong convergence is often much more desirable than weak convergence, for it translates the physically tangible property that the energy $\left\|x_{n}-x\right\|$ of the error between the iterate $x_{n}$ and the solution $x$ eventually becomes arbitrarily small. We also remark here that many authors have been instigating the problem of modifying the normal Mann iteration process to have strong convergence for $\kappa$-strictly pseudocontractive mappings; see [24-27] and the references therein.

Let $D$ be a nonempty subset of $C$. Let $Q: C \rightarrow D$. $Q$ is said to be a contraction iff $Q^{2}=Q$; sunny iff for each $x \in C$ and $t \in(0,1)$, we have $Q(t x+(1-t) Q x)=Q x$; sunny nonexpansive retraction iff $Q$ is sunny, nonexpansive and a contraction. $K$ is said to be a nonexpansive retract of $C$ if there exists a nonexpansive retraction from $C$ onto $D$. The following result, which was established in [39], describes a characterization of sunny nonexpansive retractions on a smooth Banach space. 
Let $Q: E \rightarrow C$ be a retraction, and let $j$ be the normalized duality mapping on $E$. Then the following are equivalent:

(1) $Q$ is sunny and nonexpansive;

(2) $\|Q x-Q y\|^{2} \leq\langle x-y, j(Q x-Q y)\rangle, \forall x, y \in E$;

(3) $\langle x-Q x, j(y-Q x)\rangle \leq 0, \forall x \in E, y \in C$.

In this paper, we investigate the problem of modifying the normal Mann iteration process for a family of $\kappa$-strictly pseudocontractive mappings. Strong convergence of the purposed iterative process is obtained in a real $q$-uniformly Banach space. In order to prove our main results, we need the following tools.

Lemma 2.1 [27] Let $C$ be a nonempty subset of a real q-uniformly smooth Banach space E, and let $T: C \rightarrow C$ be a $\kappa$-strict pseudocontraction. For $\alpha \in(0,1)$, we define $T_{\alpha} x=(1-\alpha) x+$ $\alpha$ Tx for every $x \in C$. Then, as $\alpha \in(0, \mu]$, where $\mu=\min \left\{1,\left\{\frac{q \kappa}{D}\right\}^{\frac{1}{q-1}}\right\}, T_{\alpha}$ is nonexpansive such that $F\left(T_{\alpha}\right)=F(T)$.

Lemma 2.2 [40] Let E be a real q-uniformly smooth Banach space. Then the following inequality holds:

$$
\|x+y\|^{q} \leq\|x\|^{q}+q\left\langle y, J_{q} x\right\rangle+D\|y\|^{q}, \quad \forall x, y \in E
$$

where $D$ is some fixed positive constant.

Lemma 2.3 [41] Assume that $\left\{a_{n}\right\}$ is a sequence of nonnegative real numbers such that

$$
a_{n+1} \leq\left(1-t_{n}\right) a_{n}+b_{n}+0\left(t_{n}\right)
$$

where $\left\{b_{n}\right\}$ and $\left\{t_{n}\right\}$ satisfy the following restrictions:

(i) $t_{n} \rightarrow 0, \sum_{n=1}^{\infty} t_{n}=\infty$;

(ii) $\sum_{n=1}^{\infty}\left|b_{n}\right|<\infty$.

Then $\lim _{n \rightarrow \infty} a_{n}=0$.

Lemma 2.4 [42] Let $\left\{x_{n}\right\}$ and $\left\{y_{n}\right\}$ be bounded sequences in a Banach space $X$, and let $\left\{\beta_{n}\right\}$ be a sequence in $[0,1]$ with

$$
0<\liminf _{n \rightarrow \infty} \beta_{n} \leq \limsup _{n \rightarrow \infty} \beta_{n}<1 .
$$

Suppose $x_{n+1}=\left(1-\beta_{n}\right) y_{n}+\beta_{n} x_{n}$ for all integers $n \geq 0$ and

$$
\limsup _{n \rightarrow \infty}\left(\left\|y_{n+1}-y_{n}\right\|-\left\|x_{n+1}-x_{n}\right\|\right) \leq 0 .
$$

Then $\lim _{n \rightarrow \infty}\left\|y_{n}-x_{n}\right\|=0$.

Lemma 2.5 [25] Let E be a smooth Banach space, and let $C$ be a nonempty convex subset of E. Given an integer $N \geq 1$, assume that $\left\{T_{i}\right\}_{i=1}^{N}: C \rightarrow C$ is a finite family of $\kappa_{i}$-strict pseudocontractions such that $\bigcap_{i=1}^{N} F\left(T_{i}\right) \neq \emptyset$. Assume that $\left\{\lambda_{i}\right\}_{i=1}^{r}$ is a positive sequence such that $\sum_{i=1}^{N} \lambda_{i}=1$. Then $F\left(\sum_{i=1}^{N} F\left(T_{i}\right)\right)=\bigcap_{i=1}^{N} F\left(T_{i}\right)$. 
Lemma 2.6 [43] Let $q>1$. Then the following inequality holds:

$$
a b \leq \frac{a^{q}}{q}+\frac{(q-1) b^{\frac{q}{q-1}}}{q}
$$

for arbitrary positive real numbers $a$ and $b$.

\section{Main results}

Theorem 3.1 Let $C$ be a nonempty closed convex subset of a real q-uniformly smooth Banach space $E$, and let $N$ be some positive integer. Let $T_{i}: C \rightarrow C$ be a $\kappa_{i}$-strictly pseudocontractive mapping for each $1 \leq i \leq N$. Assume that $\bigcap_{i=1}^{N} F\left(T_{i}\right) \neq \emptyset$. Let $f$ be an $\alpha$-contractive mapping. Let $\left\{x_{n}\right\}$ be a sequence generated in the following process:

$$
\left\{\begin{array}{l}
x_{0} \in C \quad \text { arbitrarily chosen, } \\
y_{n}=\left(1-\delta_{n}\right) x_{n}+\delta_{n} \sum_{i=1}^{N} \lambda_{i} T_{i} x_{n}, \\
x_{n+1}=\alpha_{n} f\left(x_{n}\right)+\beta_{n} x_{n}+\gamma_{n} y_{n}, \quad n \geq 0,
\end{array}\right.
$$

where $\left\{\alpha_{n}\right\},\left\{\beta_{n}\right\}$ and $\left\{\lambda_{i}\right\}$ are real number sequences in $[0,1]$ satisfying the following restrictions:

(a) $\alpha_{n}+\beta_{n}+\gamma_{n}=1$

(b) $\sum_{n=0}^{\infty} \alpha_{n}=\infty, \lim _{n \rightarrow \infty} \alpha_{n}=0$;

(c) $0<\liminf _{n \rightarrow \infty} \beta_{n} \leq \limsup _{n \rightarrow \infty} \beta_{n}<1$;

(d) $\lim _{n \rightarrow \infty}\left\|\delta_{n+1}-\delta_{n}\right\|=0, \delta \leq \delta_{n} \leq \min \left\{1,\left\{\frac{q \kappa}{D}\right\}^{\frac{1}{q-1}}\right\}$;

(e) $\sum_{i=1}^{N} \lambda_{i}=1$,

where $\delta>0$ is some real number, and $\kappa:=\min \left\{\kappa_{i}: 1 \leq i \leq N\right\}$. Then $\left\{x_{n}\right\}$ converges strongly as $n \rightarrow \infty$ to some point in $\bigcap_{i=1}^{N} F\left(T_{i}\right)$, which is the unique solution in $\bigcap_{i=1}^{N} F\left(T_{i}\right)$ to the following variational inequality:

$$
\left\langle f(z)-z, j_{q}(z-p)\right\rangle \geq 0, \quad \forall p \in \bigcap_{i=1}^{N} F\left(T_{i}\right)
$$

Proof First, we show that $\left\{x_{n}\right\}$ and $\left\{y_{n}\right\}$ are bounded. Putting $T:=\sum_{i=1}^{N} \lambda_{i} T_{i}$, we see that $T$ is a $\kappa$-strictly pseudocontractive mapping. Indeed, we have the following:

$$
\begin{aligned}
\langle T x- & T y, j(x-y)\rangle \\
= & \lambda_{1}\left\langle T_{1} x-T_{1} y, j(x-y)\right\rangle+\lambda_{2}\left\langle T_{2} x-T_{2} y, j(x-y)\right\rangle+\cdots+\lambda_{N}\left\langle T_{N} x-T_{N} y, j(x-y)\right\rangle \\
\leq & \lambda_{1}\left(\|x-y\|^{2}-\kappa_{1}\left\|\left(I-T_{1}\right) x-\left(I-T_{1}\right) y\right\|^{2}\right) \\
& +\lambda_{2}\left(\|x-y\|^{2}-\kappa_{2}\left\|\left(I-T_{2}\right) x-\left(I-T_{2}\right) y\right\|^{2}\right)+\cdots \\
& +\lambda_{N}\left(\|x-y\|^{2}-\kappa_{N}\left\|\left(I-T_{N}\right) x-\left(I-T_{N}\right) y\right\|^{2}\right) \\
\leq & \|x-y\|^{2}-\kappa\left(\lambda_{1}\left\|\left(I-T_{1}\right) x-\left(I-T_{1}\right) y\right\|^{2}\right. \\
& \left.+\lambda_{2}\left\|\left(I-T_{2}\right) x-\left(I-T_{2}\right) y\right\|^{2}+\cdots+\lambda_{N}\left\|\left(I-T_{N}\right) x-\left(I-T_{N}\right) y\right\|^{2}\right) \\
\leq & \|x-y\|^{2}-\kappa\|(I-T) x-(I-T) y\|^{2} .
\end{aligned}
$$


This proves that $T$ is a $\kappa$-strictly pseudocontractive mapping. Fix $p \in \bigcap_{i=1}^{N} F\left(T_{i}\right)$ and put $T_{\delta_{n}} x=\left(1-\delta_{n}\right) x+\delta_{n} T x, \forall x \in C$. It follows from Lemma 2.1 that $T_{\delta_{n}}$ is nonexpansive. This in turn implies that

$$
\left\|y_{n}-p\right\| \leq\left\|x_{n}-p\right\|
$$

It follows that

$$
\begin{aligned}
\left\|x_{n+1}-p\right\| & =\left\|\alpha_{n}\left(f\left(x_{n}\right)-p\right)+\beta_{n}\left(x_{n}-p\right)+\gamma_{n}\left(y_{n}-p\right)\right\| \\
& \leq \alpha_{n}\left\|f\left(x_{n}\right)-f(p)\right\|+\alpha_{n}\|p-f(p)\|+\beta_{n}\left\|x_{n}-p\right\|+\gamma_{n}\left\|y_{n}-p\right\| \\
& \leq \alpha_{n} \alpha\left\|x_{n}-p\right\|+\alpha_{n}\|p-f(p)\|+\beta_{n}\left\|x_{n}-p\right\|+\gamma_{n}\left\|y_{n}-p\right\| \\
& \leq\left(1-\alpha_{n}(1-\alpha)\right)\left\|x_{n}-p\right\|+\alpha_{n}\|p-f(p)\| \\
& \leq \max \left\{\left\|x_{n}-p\right\|, \frac{\|f(p)-p\|}{1-\alpha}\right\} .
\end{aligned}
$$

This in turn implies that

$$
\left\|x_{n}-p\right\| \leq \max \left\{\left\|x_{0}-p\right\|, \frac{\|p-f(p)\|}{1-\alpha}\right\}
$$

which gives that the sequence $\left\{x_{n}\right\}$ is bounded, so is $\left\{y_{n}\right\}$. Notice that

$$
\begin{aligned}
\left\|y_{n+1}-y_{n}\right\| & =\left\|T_{\delta_{n+1}} x_{n+1}-T_{\delta_{n}} x_{n}\right\| \\
& \leq\left\|T_{\delta_{n+1}} x_{n+1}-T_{\delta_{n+1}} x_{n}\right\|+\left\|T_{\delta_{n+1}} x_{n}-T_{\delta_{n}} x_{n}\right\| \\
& \leq\left\|x_{n+1}-x_{n}\right\|+\left\|\delta_{n+1} x_{n}+\left(1-\delta_{n+1}\right) T x_{n}-\delta_{n} x_{n}-\left(1-\delta_{n}\right) T x_{n}\right\| \\
& \leq\left\|x_{n+1}-x_{n}\right\|+\left|\delta_{n+1}-\delta_{n}\right|\left\|x_{n}-T x_{n}\right\| .
\end{aligned}
$$

Putting $t_{n}=\frac{x_{n+1}-\beta_{n} x_{n}}{1-\beta_{n}}$, we see that

$$
x_{n+1}=\left(1-\beta_{n}\right) t_{n}+\beta_{n} x_{n} .
$$

Now, we compute $t_{n+1}-t_{n}$. Noticing that

$$
\begin{aligned}
t_{n+1}-t_{n} & =\frac{\alpha_{n+1} f\left(x_{n+1}\right)+\gamma_{n+1} y_{n+1}}{1-\beta_{n+1}}-\frac{\alpha_{n} f\left(x_{n}\right)+\gamma_{n} y_{n}}{1-\beta_{n}} \\
& =\frac{\alpha_{n+1}}{1-\beta_{n+1}} f\left(x_{n+1}\right)+\frac{1-\beta_{n+1}-\alpha_{n+1}}{1-\beta_{n+1}} y_{n+1}-\frac{\alpha_{n}}{1-\beta_{n}} f\left(x_{n}\right)-\frac{1-\beta_{n}-\alpha_{n}}{1-\beta_{n}} y_{n} \\
& =\frac{\alpha_{n+1}}{1-\beta_{n+1}}\left(f\left(x_{n+1}\right)-y_{n+1}\right)+\frac{\alpha_{n}}{1-\beta_{n}}\left(y_{n}-f\left(x_{n}\right)\right)+y_{n+1}-y_{n},
\end{aligned}
$$

we have

$$
\left\|t_{n+1}-t_{n}\right\| \leq \frac{\alpha_{n+1}}{1-\beta_{n+1}}\left\|f\left(x_{n+1}\right)-y_{n+1}\right\|+\frac{\alpha_{n}}{1-\beta_{n}}\left\|y_{n}-f\left(x_{n}\right)\right\|+\left\|y_{n+1}-y_{n}\right\| .
$$


Substituting (3.2) into (3.4), we arrive at

$$
\begin{aligned}
\left\|t_{n+1}-t_{n}\right\|-\left\|x_{n+1}-x_{n}\right\| \leq & \frac{\alpha_{n+1}}{1-\beta_{n+1}}\left\|f\left(x_{n+1}\right)-y_{n+1}\right\|+\frac{\alpha_{n}}{1-\beta_{n}}\left\|y_{n}-f\left(x_{n}\right)\right\| \\
& +\left|\delta_{n+1}-\delta_{n}\right|\left\|x_{n}-T x_{n}\right\| .
\end{aligned}
$$

It follows from the restrictions (b) and (c) that

$$
\lim _{n \rightarrow \infty}\left\|t_{n+1}-t_{n}\right\|-\left\|x_{n+1}-x_{n+1}\right\|<0
$$

In view of Lemma 2.4, we obtain that $\lim _{n \rightarrow \infty}\left\|t_{n}-x_{n}\right\|=0$. This implies from the restriction (c) that

$$
\lim _{n \rightarrow \infty}\left\|x_{n+1}-x_{n}\right\|=0
$$

Notice that

$$
x_{n+1}-x_{n}=\alpha_{n}\left(f\left(x_{n}\right)-x_{n}\right)+\gamma_{n}\left(y_{n}-x_{n}\right) \text {. }
$$

It follows that $\lim _{n \rightarrow \infty}\left\|y_{n}-x_{n}\right\|=0$. On the other hand, we have $y_{n}-x_{n}=\delta_{n}\left(T x_{n}-x_{n}\right)$. It follows that $\lim _{n \rightarrow \infty}\left\|T x_{n}-x_{n}\right\|=0$. This in turn implies that

$$
\lim _{n \rightarrow \infty}\left\|T_{\mu} x_{n}-x_{n}\right\|=0,
$$

where $\mu=\min \left\{1,\left\{\frac{q \kappa}{D}\right\}^{\frac{1}{q-1}}\right\}$. Next, we show that

$$
\limsup _{n \rightarrow \infty}\left\langle z-f(z), j_{q}\left(z-x_{n}\right)\right\rangle \leq 0
$$

where $z=Q f(z)$, where $Q$ is a sunny nonexpansive retraction from $C$ onto $\bigcap_{i=1}^{N} F\left(T_{i}\right)$, is the strong limit of the sequence $z_{t}$ defined by

$$
z_{t}=t f\left(z_{t}\right)+(1-t) T_{\mu} z_{t}, \quad \forall t \in(0,1)
$$

It follows that

$$
z_{t}-x_{n}=(1-t)\left(T_{\mu} z_{t}-x_{n}\right)+t\left(f\left(z_{t}\right)-x_{n}\right), \quad \forall t \in(0,1) .
$$

For any $t \in(0,1)$, we see that

$$
\begin{aligned}
\left\|z_{t}-x_{n}\right\|^{q} & =t\left\langle f\left(z_{t}\right)-x_{n}, j_{q}\left(z_{t}-x_{n}\right)\right\rangle+(1-t)\left\langle T_{\mu} z_{t}-x_{n}, j_{q}\left(z_{t}-x_{n}\right)\right\rangle \\
& \leq t\left\langle f\left(z_{t}\right)-x_{n}, j_{q}\left(z_{t}-x_{n}\right)\right\rangle+(1-t)\left\|z_{t}-x_{n}\right\|^{q}+M\left\|T_{\mu} x_{n}-x_{n}\right\|
\end{aligned}
$$

where $M=\sup \left\{\left\|x_{n}-z_{t}\right\|^{q-1}: t \in(0,1), n \geq 0\right\}$. It follows that

$$
\left\langle f\left(z_{t}\right)-x_{t}, j_{q}\left(x_{n}-z_{t}\right)\right\rangle \leq \frac{M}{t}\left\|T_{\mu} x_{n}-x_{n}\right\| .
$$


Fixing $t$ and letting $n \rightarrow \infty$ yields that

$$
\limsup _{n \rightarrow \infty}\left\{f\left(z_{t}\right)-x_{t}, j_{q}\left(x_{n}-z_{t}\right)\right\rangle \leq 0
$$

Since $E$ is $q$-uniformly smooth, $J_{q}: E \rightarrow E^{*}$ is uniformly continuous on any bounded sets of $E$, which ensures that limsup $\operatorname{su}_{n \rightarrow \infty}$ and $\limsup _{t \rightarrow 0}$ are interchangeable, hence

$$
\limsup _{n \rightarrow \infty}\left\langle z-f(z), j_{q}\left(z-x_{n}\right)\right\rangle \leq 0
$$

Finally, we show that $x_{n} \rightarrow z$ as $n \rightarrow \infty$. In view of Lemma 2.6, we see that

$$
\begin{aligned}
\left\|x_{n+1}-z\right\|^{q}= & \alpha_{n}\left\langle f\left(x_{n}\right)-z, j_{q}\left(x_{n+1}-z\right)\right\rangle+\beta_{n}\left\langle x_{n}-z, j_{q}\left(x_{n+1}-z\right)\right\rangle \\
& +\gamma_{n}\left\langle y_{n}-z, j_{q}\left(x_{n+1}-z\right)\right\rangle \\
\leq & \alpha_{n}\left\langle f\left(x_{n}\right)-z, j_{q}\left(x_{n+1}-z\right)\right\rangle+\beta_{n}\left\|x_{n}-z\right\|\left\|x_{n+1}-z\right\|^{q-1} \\
& +\gamma_{n}\left\|y_{n}-z\right\|\left\|x_{n+1}-z\right\|^{q-1} \\
\leq & \alpha_{n} \lambda_{n}+\left(1-\alpha_{n}\right)\left\|x_{n}-z\right\|\left\|x_{n+1}-z\right\|^{q-1} \\
\leq & \alpha_{n} \lambda_{n}+\left(1-\alpha_{n}\right) \frac{\left\|x_{n}-z\right\|^{q}}{q}+\frac{q-1}{q}\left\|x_{n+1}-z\right\|^{q},
\end{aligned}
$$

where $\lambda_{n}=\max \left\{\left\langle f\left(x_{n}\right)-z, j_{q}\left(x_{n+1}-z\right)\right\rangle, 0\right\}$. This implies that

$$
\left\|x_{n+1}-z\right\|^{q} \leq q \alpha_{n} \lambda_{n}+\left(1-\alpha_{n}\right)\left\|x_{n}-z\right\|^{q} .
$$

In view of Lemma 2.3, we find the desired conclusion immediately. This completes the proof.

Remark 3.2 Theorem 3.1 mainly improves the corresponding results in Yuan et al. [22] from 2-uniformly smooth Banach spaces to $q$-uniformly smooth Banach spaces. Theorem 3.1 is applicable to the spaces $l^{p}$ and $L^{p}$ for all $q>1$.

From Theorem 3.1, we have the following result immediately.

Corollary 3.3 Let $C$ be a nonempty closed convex subset of a real q-uniformly smooth Banach space $E$, and let $N$ be some positive integer. Let $T_{i}: C \rightarrow C$ be a $\kappa_{i}$-strictly pseudocontractive mapping for each $1 \leq i \leq N$. Assume that $\bigcap_{i=1}^{N} F\left(T_{i}\right) \neq \emptyset$. Let $\left\{x_{n}\right\}$ be a sequence generated in the following process:

$$
\left\{\begin{array}{l}
x_{0} \in C \quad \text { arbitrarilychosen, } \\
y_{n}=\left(1-\delta_{n}\right) x_{n}+\delta_{n} \sum_{i=1}^{N} \lambda_{i} T_{i} x_{n}, \\
x_{n+1}=\alpha_{n} u+\beta_{n} x_{n}+\gamma_{n} y_{n}, \quad n \geq 0,
\end{array}\right.
$$

where $u$ is a fixed element in $C,\left\{\alpha_{n}\right\},\left\{\beta_{n}\right\}$ and $\left\{\lambda_{i}\right\}$ are real number sequences in $[0,1]$ satisfying the following restrictions:

(a) $\alpha_{n}+\beta_{n}+\gamma_{n}=1$ 
(b) $\sum_{n=0}^{\infty} \alpha_{n}=\infty, \lim _{n \rightarrow \infty} \alpha_{n}=0$;

(c) $0<\liminf _{n \rightarrow \infty} \beta_{n} \leq \limsup _{n \rightarrow \infty} \beta_{n}<1$;

(d) $\lim _{n \rightarrow \infty}\left\|\delta_{n+1}-\delta_{n}\right\|=0, \delta \leq \delta_{n} \leq \min \left\{1,\left\{\frac{q \kappa}{D}\right\}^{\frac{1}{q-1}}\right\}$

(e) $\sum_{i=1}^{N} \lambda_{i}=1$,

where $\delta>0$ is some real number, and $\kappa:=\min \left\{\kappa_{i}: 1 \leq i \leq N\right\}$. Then $\left\{x_{n}\right\}$ converges strongly as $n \rightarrow \infty$ to some point in $\bigcap_{i=1}^{N} F\left(T_{i}\right)$, which is the unique solution in $\bigcap_{i=1}^{N} F\left(T_{i}\right)$ to the following variational inequality:

$$
\langle u-z, j(z-p)\rangle \geq 0, \quad \forall p \in \bigcap_{i=1}^{N} F\left(T_{i}\right) .
$$

Remark 3.4 Corollary 3.3 improves the corresponding results in Zhou [26] from 2uniformly smooth Banach spaces to $q$-uniformly smooth Banach spaces and relaxes the restrictions imposed on the parameter $\left\{\lambda_{i}\right\}$ in Zhang and $\mathrm{Su}$ [27].

\section{Competing interests}

The authors declare that they have no competing interests.

\section{Authors' contributions}

All authors contributed equally to this work. All authors read and approved the final manuscript.

\section{Author details}

${ }^{1}$ Department of Mathematics, Hangzhou Normal University, Hangzhou, China. ${ }^{2}$ Department of Mathematics,

Shijiazhuang University, Shijiazhuang, China. ${ }^{3}$ School of Science, Beijing Jiaotong University, Beijing, China.

\section{Acknowledgements}

The first author was supported by the Natural Science Foundation of Zhejiang Province (Q12A010097) and the National Natural Science Foundation of China (11126334). The second author was supported by the Fundamental Research Funds for the Central Universities of China (2011YJS075) and the Scientific Research Fund of Hebei Provincial Education Department (QN20132030). The authors are grateful to the editor and two anonymous reviewers' suggestions which improved the contents of the article.

Received: 15 July 2013 Accepted: 14 October 2013 Published: 11 Nov 2013

\section{References}

1. Park, S: A review of the KKM theory on $\phi_{A}$-space or GFC-spaces. Adv. Fixed Point Theory 3, 355-382 (2013)

2. Cho, SY, Li, W, Kang, SM: Convergence analysis of an iterative algorithm for monotone operators. J. Inequal. Appl. 2013, Article ID 199 (2013)

3. Dhage, BC, Nashine, HK, Patil, VS: Common fixed points for some variants of weakly contraction mappings in partially ordered metric spaces. Adv. Fixed Point Theory 3, 29-48 (2013)

4. Cho, SY, Kang, SM: Approximation of fixed points of pseudocontraction semigroups based on a viscosity iterative process. Appl. Math. Lett. 24, 224-228 (2011)

5. Dhage, BC, Jadhav, NS: Differential inequalities and comparison theorems for first order hybrid integro-differential equations. Adv. Inequal. Appl. 2,61-80 (2013)

6. Qin, X, Cho, SY, Kang, SM: An extragradient-type method for generalized equilibrium problems involving strictly pseudocontractive mappings. J. Glob. Optim. 49, 679-693 (2011)

7. Chen, JH: Fixed point iterations of semigroups of nonexpansive mappings. J. Semigroup Theory Appl. 2013, Article ID 9 (2013)

8. Wang, ZM, Lou, W: A new iterative algorithm of common solutions to quasi-variational inclusion and fixed point problems. J. Math. Comput. Sci. 3, 57-72 (2013)

9. Lv, S, Wu, C: Convergence of iterative algorithms for a generalized variational inequality and a nonexpansive mapping. Eng. Math. Lett. 1, 44-57 (2012)

10. Noor, MA, Noor, Kl, Waseem, M: Decomposition method for solving system of linear equations. Eng. Math. Lett. 2 34-41 (2013)

11. Cho, SY, Kang, SM: Approximation of common solutions of variational inequalities via strict pseudocontractions. Acta Math. Sci. 32, 1607-1618 (2012)

12. Shen, J, Pang, LP: An approximate bundle method for solving variational inequalities. Commun. Optim. Theory 1 , 1-18 (2012)

13. Fattorini, HO: Infinite-Dimensional Optimization and Control Theory. Cambridge University Press, Cambridge (1999)

14. Dhage, BC, Kamble, GP, Metkar, RG: On generalized Mellin-Hardy integral transformations. Eng. Math. Lett. 2, 67-80 (2013) 
15. Lions, PL, Mercier, B: Splitting algorithms for the sum of two nonlinear operators. SIAM J. Numer. Anal. 16, 964-979 (1979)

16. Al-Bayati, AY, Al-Kawaz, RZ: A new hybrid WC-FR conjugate gradient-algorithm with modified secant condition for unconstrained optimization. J. Math. Comput. Sci. 2, 937-966 (2012)

17. Cho, SY, Qin, X, Kang, SM: Iterative processes for common fixed points of two different families of mappings with applications. J. Glob. Optim. (2013). doi:10.1007/s10898-012-0017-y

18. Chen, JH: Iterations for equilibrium and fixed point problems. J. Nonlinear Funct. Anal. 2013, Article ID 4 (2013)

19. Osu, BO, Solomon, OU: A stochastic algorithm for the valuation of financial derivatives using the hyperbolic distributional variates. Math. Finance Lett. 1, 43-56 (2012)

20. Qin, X, Cho, SY, Kang, SM: Iterative algorithms for variational inequality and equilibrium problems with applications. J. Glob. Optim. 48, 423-445 (2010)

21. Kangtunyakarn, A, Suantai, S: Strong convergence of a new iterative scheme for a finite family of strict pseudo-contractions. Comput. Math. Appl. 60, 680-694 (2010)

22. Yuan, Q, Cho, SY, Shang, M: Strong convergence of an iterative process for a family of strictly pseudocontractive mappings. Fixed Point Theory Appl. 2013, Article ID 117 (2013)

23. Qin, X, Cho, YJ, Kang, SM, Shang, MJ: A hybrid iterative scheme for asymptotically $\kappa$-strict pseudo-contractions in Hilbert spaces. Nonlinear Anal. 70, 1902-1911 (2009)

24. Qin, X, Shang, M, Kang, SM: Strong convergence theorems of modified Mann iterative process for strict pseudo-contractions in Hilbert spaces. Nonlinear Anal. 70, 1257-1264 (2009)

25. Zhou, $\mathrm{H}$ : Strong convergence of an explicit iterative algorithm for continuous pseudo-contractions in Banach spaces. Nonlinear Anal. 70, 4039-4046 (2009)

26. Zhou, $\mathrm{H}$ : Convergence theorems for $\lambda$-strict pseudo-contractions in 2-uniformly smooth Banach spaces. Nonlinear Anal. 69, 3160-3173 (2008)

27. Zhang, H, Su, Y: Strong convergence theorems for strict pseudo-contractions in q-uniformly smooth Banach spaces. Nonlinear Anal. 70, 3236-3242 (2009)

28. Wang, ZM: Convergence theorem on total asymptotically pseudocontractive mapping. J. Math. Comput. Sci. 3 , 788-798 (2013)

29. Ceng, LC, Yao, JC: Strong convergence theorems for variational inequalities and fixed point problems of asymptotically strict pseudocontractive mappings in the intermediate sense. Acta Appl. Math. 115, 167-191 (2011)

30. Takahshi, W, Wong, NC, Yao, JC: Iterative common solutions for monotone inclusion problems, fixed point problems and equilibrium problems. Fixed Point Theory Appl. 2012, Article ID 181 (2012)

31. Ceng, LC, Ansari, QH, Yao, JC: Strong and weak convergence theorems for asymptotically strict pseudocontractive mappings in intermediate sense. J. Nonlinear Convex Anal. 11, 283-308 (2010)

32. Kotzer, T, Cohen, N, Shamir, J: Image restoration by a novel method of parallel projection onto constraint sets. Opt. Lett. 20, 1172-1174 (1995)

33. Sezan, MI, Stark, H: Application of convex projection theory to image recovery in tomograph and related areas. In: Stark, H (ed.) Image Recovery: Theory and Application, pp. 155-270. Academic Press, Orlando (1987)

34. Censor, Y, Zenios, SA: Parallel Optimization: Theory, Algorithms, and Applications. Numerical Mathematics and Scientific Computation. Oxford University Press, New York (1997)

35. Browder, FE, Petryshyn, WV: Construction of fixed points of nonlinear mappings in Hilbert spaces. J. Math. Anal. Appl. 20, 197-228 (1967)

36. Browder, FE: Convergence of approximants to fixed points of nonexpansive nonlinear mappings in Banach space. Arch. Ration. Mech. Anal. 24, 82-90 (1967)

37. Reich, S: Weak convergence theorems for nonexpansive mappings in Banach spaces. J. Math. Anal. Appl. 67, 274-276 (1979)

38. Xu, HK: Viscosity approximation methods for nonexpansive mappings. J. Math. Anal. Appl. 298, $279-291$ (2004)

39. Bruck, RE: Nonexpansive projections on subsets of Banach spaces. Pac. J. Math. 47, 341-355 (1973)

40. Xu, HK: Inequalities in Banach spaces with applications. Nonlinear Anal. 16, 1127-1138 (1991)

41. Liu, LS: Ishikawa and Mann iteration process with errors for nonlinear strongly accretive mappings in Banach spaces. J. Math. Anal. Appl. 194, 114-125 (1995)

42. Suzuki, T: Strong convergence of Krasnoselskii and Mann's type sequences for one-parameter nonexpansive semigroups without Bochne integrals. J. Math. Anal. Appl. 305, 227-239 (2005)

43. Mitrinovic, DS: Analytic Inequalities. Springer, New York (1970)

10.1186/1687-1812-2013-298

Cite this article as: Qin et al.: Common fixed points of a family of strictly pseudocontractive mappings. Fixed Point Theory and Applications 2013, 2013:298 